\title{
Dynamic slab segmentation due to brittle-ductile damage interactions in the outer rise
}

Taras Gerya ( $\nabla$ taras.gerya@erdw.ethz.ch )

ETH-Zurich https://orcid.org/0000-0002-1062-2722

\section{David Bercovici}

Yale University

\section{Thorsten Becker}

The University of Texas https://orcid.org/0000-0002-5656-4564

\section{Physical Sciences - Article}

Keywords: Oceanic Plate Recycling, Thermo-clinical Evolution, Subduction Trenches, Bending Memory

Posted Date: November 30th, 2020

DOl: https://doi.org/10.21203/rs.3.rs-85800/v1

License: (1) This work is licensed under a Creative Commons Attribution 4.0 International License. Read Full License

Version of Record: A version of this preprint was published at Nature on November 10th, 2021. See the published version at https://doi.org/10.1038/s41586-021-03937-x. 
1 Dynamic slab segmentation due to brittle-ductile damage interactions in the

2 outer rise

$4 \quad$ T. V. Gerya ${ }^{1}$, D. Bercovici² \& T. W. Becker ${ }^{3.4}$

5 1Swiss Federal Institute of Technology Zurich, Department of Earth Sciences, Zurich,

6 Switzerland.

$7 \quad$ 2Yale University, Earth \& Planetary Science, New Haven, CT, United States

8 3Institute for Geophysics, Jackson School of Geosciences, The University of Texas at

9 Austin, Austin, TX, United States

$10{ }^{4}$ Department of Geological Sciences, Jackson School of Geosciences, The University of

11 Texas at Austin, Austin, TX, United States

15 The recycling of oceanic plates by means of subduction represents the major

16 plate driving force and subducting plate strength controls many aspects of the

17 thermo-chemical evolution of Earth. Regardless of its prior history, each

18 subducting plate experiences intense normal faulting ${ }^{1-11}$ during bending that

19 accommodates the transition from horizontal to downward motion at the

20 outer rise at subduction trenches. Here, we investigate the consequences of

21 this bending-induced plate damage using new numerical, thermomechanical

22 subduction models in which both brittle and ductile deformation, as well as

23 grain size evolution, are tracked and coupled self-consistently. Pervasive slab

24 weakening and pronounced segmentation can occur at the outer rise region

25 due to the strong feedback between brittle and ductile damage localization.

26 The "memory" of bending varies from segmentation to broadly-distributed

27 damage depending on the age of the subducting plate, mantle potential

28 temperature, and the magnitude of strain-induced weakening of outer rise

29 normal faults. This new slab damage phenomenon explains the development 
of large-offset normal faults ${ }^{8,9}$, the occurrence of deep compressional thrust-

31 faulting earthquakes ${ }^{12}$, and the appearance of localized areas of reduced

32 effective viscosity ${ }^{13}$ observed at subduction trenches. Furthermore, brittle-

33 viscously damaged slabs show a strong tendency for slab breakoff at elevated

34 mantle temperatures. Given Earth's planetary cooling history ${ }^{14}$, this implies

35 that intermittent subduction with frequent slab breakoff episodes ${ }^{15,16}$ may

36 have been characteristic for terrestrial plate tectonics until more recent times than expected from memory-free rheologies ${ }^{17}$.

Subduction of negatively buoyant oceanic lithosphere is a key driver of terrestrial tectonics. Subduction results from buoyancy forces that bend and pull the lithosphere into the interior of the Earth's mantle where mechanical properties of

42 subducted lithospheric slabs are strongly modified by various physical-chemical

43 processes ${ }^{18-20}$. One of the large-scale effects of this modification is the pronounced

44 mechanical dichotomy of stronger lithospheric plates at the surface and weaker

45 slabs in the Earth's interior that has been proposed on the basis of various

46 geological-geophysical data combined with numerical modeling ${ }^{20-22}$. Whereas strong

47 plates at the surface are a pre-requisite for terrestrial style one-sided

48 subduction ${ }^{15,20,23}$ weakened lithospheric subducted slabs, which pile, bend, segment

49 or lie flat at the top of the lower mantle, are needed to reproduce the spectrum of

50 slab morphologies observed on Earth ${ }^{24,25}$ as well as the observed variations of the

51 Earth's geoid ${ }^{18,26}$. Slab weakening seems in apparent contradiction with

52 experimentally calibrated, thermally activated rheological laws for the lithospheric

53 mantle 27,28 , which predict high effective viscosity ( $>10^{24} \mathrm{~Pa} \mathrm{~s}$ ) of subducted slabs in

54 the upper mantle ${ }^{18,29}$, implying a slab/mantle viscosity contrast of $>>1000$. In

55 contrast, a number of observations, combined with modeling studies, suggest that

56 this contrast should be much lower (of the order of 100) ) $^{19,22,24,30}$, for example to

57 reconcile the dynamics with seismic tomography models that indicate strong

58 deformation and even disruption of subducted slabs in the upper mantle $24,25,31$.

59 The apparent rheological paradox of strong plates and weak slabs ${ }^{20,24}$ can be

60 resolved by assuming some additional lithospheric weakening processes that are 
61 intrinsically related to the transition from horizontal plate motion to its diving into

62 the mantle. In this respect, plate bending at the outer rise is a primary candidate for

63 changing the mechanical properties of the lithosphere ${ }^{5,6,19}$. Each subducting plate,

64 irrespective of its age and earlier history, unavoidably experiences a transition from

65 its horizontal to vertical motion through bending when passing through the outer

66 rise region that is present at every subduction trench. Plate bending is not fully

67 elastic and is associated with a number of irreversible physical-chemical processes

68 that can profoundly change the mechanical properties of the subducting plate $1,5,8-$

6910,19 . As the result, the elastic strength of the plate is completely lost within $100 \mathrm{~km}$

70 of the trench axis through faulting and ductile deformation. This requires that

71 coupling of the slab to the plate occurs through viscous stresses, making the trench

72 topography a dynamic feature ${ }^{19}$.

73 It is well understood that the colder, brittle top region of subducting plates is

74 pervasively damaged by extensional outer rise normal faulting ${ }^{1,4,9,11,19}$, possibly

75 associated with downward water penetration and mantle lithosphere

76 serpentinization, $23,5-7,10$. In contrast, the deeper and warmer portions of the plate

77 deform in compression by viscous creep ${ }^{13,32}$ and can potentially be affected by

78 ductile damage processes such as grain size reduction assisted by Zener pinning ${ }^{33-38}$.

79 Relating these brittle and ductile damage processes to the plate bending at the outer

80 rise can advance our understanding of whether and how the pervasive weakening of

81 subducting plates may occur in nature and what consequences that deformation

82 memory will have for the dynamics and stability of subduction.

83 Here, we investigate the consequences of bending-induced plate damage by

84 using new 2D numerical thermomechanical subduction models in which both

85 brittle-plastic and ductile deformation as well as grain size reduction and growth

86 are coupled self-consistently (Methods). Our modeling results indicate that brittle-

87 ductile slab weakening and plate segmentation should occur at the outer rise region

88 due to the strong feedback between brittle and ductile damage localization. 


\section{Slab segmentation by bending at the outer rise}

Figure 1 shows an example of a typical model evolution resulting in subducting slab damage and segmentation. The numerical experiment starts from subduction initiation at a transform fault ${ }^{23,39}$ which separates two oceanic plates of different ages, leading to lateral gravitational instability. The older plate starts to subduct in a retreating manner whereas the younger, now overriding plate is subjected to extension and horizontal motion toward the retreating trench. After the initial period of retreat associated with gradual downward sinking and steepening of the slab, the slab angle stabilizes and the advancing horizontal motion of the subducting plate begins. This mode of subduction continues until the slab reaches the mantle transition zone and starts to flatten due to the negative Clapeyron slope of the spinel-perovskite phase transition (Methods), which initiates a new episode of trench retreat. The viscosity of the subducting plate that results from this dynamically self-consistent subduction scenario shows a pattern of 150-200 km long segments separated by narrow low-viscosity zones. This damage pattern forms as the result of linked, localized brittle-plastic deformation and grain-size reduction at the outer rise (Fig. 2a, b). As a consequence, the subducting slab deforms easily in a chain-like fashion in response to its interaction with the mantle transition zone. The resulting slab morphologies are markedly different from those of visco-plastic slabs without damage 22,24 and reflect the influence of the strong coupling between the brittle and ductile strain localization mechanisms during plate bending. Model sensitivity studies show that the style of slab deformation depends strongly on both the ductile damage and the strain-induced weakening of faults as well as on the age of the subducting plate and the mantle potential temperature. In particular, deactivation of ductile damage (grainsize reduction) and/or straininduced weakening produces smoothly bent slabs (cf. Fig. 3a and b, c, d) comparable to previous subduction models ${ }^{15,23,24}$. Lack of ductile damage also makes subduction initiation more difficult (cf. Figs. 4a and c) due to the increased bending resistance of the subducting plate. The combined effects of fault weakening and ductile damage on slab segmentation are notably distinct from the individual forms of weakening. In the absence of normal fault weakening, slab segments disappear and grain size 
123 reduction inside the subducting plate is distributed more evenly (cf. Figs. 3a and c).

124 This, in turn, causes distributed rather than localized, segmented weakening of

125 slabs. A similar effect is achieved by decreasing the rate of fault-weakening with

126 strain (cf. Figs. 4b and c). In contrast, in the absence of ductile damage, slab

127 segments remain but the displacement along individual normal faults reduces and

128 consequently the large-offset normal faults disappear (cf. Fig. 3b). As a result, the

129 number of segments increases together with a decrease in the characteristic

130 segment length (cf. Figs. 3a and b). The total amount of deformation in each segment

131 also decreases. Slab segmentation is thus primarily driven by normal fault

132 weakening whereas the ductile damage makes this process more intense, localized

133 and laterally extensive. Ductile creep of mature faults has no influence on

134 segmentation and mainly affects the deformation of segmented slabs in the mantle:

135 weaker (serpentine type) rheology facilitates slab bending and breakoff whereas

136 stronger (dry olivine type) rheology produces less deformed slabs (Extended Data

137 Table 2).

138 The age of the subducting plate also controls the characteristic length of slab

139 segments: older and thus thicker subducting plates show longer slab segments, but

140 become much shorter in younger plates (cf. Figs. 4c and d). An increase in the

141 mantle potential temperature, in contrast, promotes slab segmentation and bending

142 by steepening of the slab angles due to the reduced amount of viscous resistance of

143 the asthenosphere to slab penetration (cf. Figs. 1 and 3a, 5a). This also leads to

144 notable acceleration of subduction and more frequent slab breakoff ${ }^{15,16}$ (cf. Figs. 1

145 and $3 a, 5 a)$.

146 Why should outer rise faults weaken with strain?

147 Our numerical models suggest that strain weakening of outer rise normal

148 faults is a key process controlling subducting slab segmentation, and is thus

149 discussed further. Strain weakening of faults is a common assumption of

150 geodynamic models ${ }^{40}$ and is crucial for reproducing a number of strain localization

151 phenomena in both oceanic and continental lithosphere such as large-offset normal

152 faults ${ }^{40}$, oceanic transform faults ${ }^{41}$, oceanic and continental core complexes ${ }^{42}$. The

153 physics of this process is incompletely understood and may include (but is not 
154 limited to) pressurized fluid percolation ${ }^{23}$, growth of hydrous minerals ${ }^{43}$, structural

155 softening ${ }^{44}$, shear heating ${ }^{45}$, coseismic weakening and grain size reduction ${ }^{46}$,

156 intergranular cavitation ${ }^{47}$. Intense hydration of outer rise normal faults has been

157 suggested on the basis of seismological, geophysical and theoretical arguments $2,3,5-$

$1587,10,12$.

159 In particular, numerical models ${ }^{5,48}$ find that the dynamic pressure associated

160 with plate bending may be large enough to overcome the confining lithostatic

161 pressure and cause downward water suction along outer rise normal faults. In

162 contrast, analytical models ${ }^{11}$ suggests that such large dynamic pressure cannot be

163 achieved, and lowered seismic velocities within the oceanic lithosphere under the

164 outer rise may instead be explained by thermal cracking. Such uncertainties

165 regarding the extent of outer rise fault hydration aside, it is clear that these

166 structures systematically reveal lowered friction coefficients $(\leq 0.3)^{12}$ compared to

167 dry oceanic lithosphere (0.6-0.85) ${ }^{49,50}$, and only such as overall weakening is what is

168 required for our simplified strain weakening models (Methods).

Evidence for segmentation of subducting slabs in nature

171 One of the testable consequences of the emergent phenomena of slab

172 segmentation is the development of large-offset normal faults localized above the

173 regions of intense grain size reduction. Like the deep slab morphology, this

174 heterogeneous faulting pattern contrasts with broadly distributed, smaller-offset

175 normal faults as produced by models without grain size reduction ${ }^{4-6}$. Large offset

176 normal faults are indeed observed at some subduction trenches, such as in Japan

177 trench, based on geological-geophysical observations ${ }^{8,9}$. Intriguingly, the deeper

178 parts of the subducting plate in Japan have been inferred to display a localized area

179 of reduced effective viscosity based on post-seismic deformation ${ }^{13}$. This zone of

180 weakening may correspond to the areas of grainsize reduction that systematically

181 develop in our models in either strongly localized (Fig. 4c) or more widely

182 distributed (Fig. 4b) manner. 
Moreover, global slab seismicity in the outer rise is often characterized by the presence of deep (20-50 km) compressional, thrust-faulting earthquakes. These earthquakes often occur below the elastic core of the subducting plate at the temperatures up to $600^{\circ} \mathrm{C}^{12}$, i.e., close to the brittle-ductile transition in the mantle lithosphere. The flow-to-friction transition near the base of the seismogenic zone may be characterized by a runaway transition from dislocation and diffusion creep to dilatant deformation, involving incompletely accommodated grain boundary sliding 47 . Localization of the compressional ductile deformation observed in our numerical experiments (Fig. 2 a,b) and controlled by grain size reduction may thus create favorable conditions for deep thrust-faulting. In the coldest parts of these

193 localized ductile deformation zones, dislocation and diffusion creep may become too

194 slow to accommodate the increasing shear strain rate, leading to intergranular

195 cavitation, weakening, strain localization, and a switch from stable flow to runaway 196 fault rupture ${ }^{47}$.

\section{Slab segmentation and occurrence of intermittent subduction}

Besides explaining these subduction zone features, the emergent phenomenon of brittle-ductile plate segmentation may have further consequences, including for the stability of modern style subduction. In the Archean, higher mantle potential temperature ${ }^{14}$ may have significantly reduced both plate strength and mantle resistance to slab penetration, and segmentation may have then induced

204 frequent slab breakoff. This could have caused punctuated, episodic (intermittent) 205 subduction $15,16,17$. Indeed, our numerical experiments performed even at modestly 206 higher temperatures of 100-150 K larger than present-day show a strong tendency 207 for slab disruption (Fig. 4a) and breakoff (Fig. 5a) in models with grain size 208 reduction compared to those without (Figs. 4b, 5b). This may imply a sensitive 209 dependence of subduction on mantle temperature, and thus possibly a larger role

210 for an intermittent style of subduction in plate tectonics during our planet's 211 cooling ${ }^{14}$ compared to what is expected from mantle convection with memory-free 212 rheologies. More generally, our models show that even oceanic lithosphere may be 213 pervasively affected by deformation history, and the associated damage memory 
214 affects not just surface deformation at trenches, but also how slabs deform and stir

215 the surroundings during their descent to the lower mantle.

216

217

218

219

220 References

221 1. Ranero, C. R., Phipps Morgan, J. \& Reichert, C. Bending-realted faulting and mantle serpentinization at the Middle America trench. Nature 425, 367-373 (2003).

2. Ranero, C.R., Sallarès, V. Geophysical evidence for hydration of the crust and mantle of the Nazca plate during bending at the north Chile trench. Geology 32, 549-552 (2004).

3. Grevemeyer, I., Ranero, C.R., Flueh, E.R., Kläschen, D., Bialas, J. Passive and active seismological study of bending-related faulting and mantle serpentinization at the Middle America trench. Earth Planet. Sci. Lett. 258, 528-542 (2007).

4. Faccenda, M., Burlini, L., Gerya, T.V., Mainprice, D. (2008) Fault-induced seismic anisotropy by hydration in subducting oceanic plates. Nature, 455, 1097-1101.

5. Faccenda, M., Gerya, T.V., Burlini, L. (2009) Deep slab hydration induced by bending related variations in tectonic pressure. Nature Geoscience, 2, 790-793.

6. Faccenda, M., Gerya, T.V., Mancktelow, N.S., Moresi, L. (2012) Fluid flow during slab unbending and dehydration: Implications for intermediate-depth seismicity, slab weakening and deep water recycling. Geochemistry, Geophysics, Geosystems, 13, Article Number: Q01010.

7. Van Avendonk, H.J.A., Holbrook, W.S., Lizarralde, D., Denyer, P. Structure and serpentinization of the subducting Cocos plate offshore Nicaragua and Costa Rica. Geochem. Geophys. Geosyst.12, Q06009 (2011).

8. Nakamura, Y., Kodaira, S., Miura, S., Regalla, C., Takahashi, N. High-resolution seismic imaging in the Japan Trench axis area off Miyagi, northeastern Japan. Geophys. Res. Let., 40, 1713-1718 (2013). 
244 9. Boston, B., Moore, G.F., Nakamura, Y., Kodaira, S. Outer-rise normal fault

245 development and influence on near-trench décollement propagation along the

246 Japan Trench, off Tohoku. Earth, Planets and Space, 66, 135 (2014).

247 10. Shillington, D. J. et al. Link between plate fabric, hydration and subduction zone 248 seismicity in Alaska. Nat. Geosci. 8(12), 961-964 (2015).

249 11. Korenaga, J. On the extent of mantle hydration caused by plate bending. Earth $250 \quad$ Planet. Sci. Let. 457, 1-9 (2017).

251 12. Craig, T. J., Copley, A., Jackson, J. A reassessment of outer-rise seismicity and its 252 implications for the mechanics of oceanic lithosphere. Geophys. J. Int. 197, 6325389 (2014).

254 13. Freed, A.M., Hashima, A., Becker, T.W. Okaya, D.A., Sato, H., Hatanaka, Y. (2017) 255 Resolving depth-dependent subduction zone viscosity and afterslip from 256 postseismic displacements following the 2011 Tohoku-oki, Japan earthquake. 257 Earth and Planetary Science Letters, 459, 279-290.

258 14. Herzberg, C. et al. Thermal history of the Earth and its petrological expression. $259 \quad$ Earth and Planet. 626 Sci. Let. 292, 79-88 (2010).

260 15. van Hunen, J., van den Berg, A. Plate tectonics on the early Earth: limitations 261 imposed by strength and buoyancy of subducted lithosphere. Lithos 103, 217$262 \quad 235$ (2008).

263 16. van Hunen, J., Moyen, J.-F. Archean subduction: fact or fiction? Annual Review of 264 Earth and Planetary Sciences 40, 195-219 (2012).

265 17. Sizova, E., Gerya, T., Brown, M., Perchuk, L.L. Subduction styles in the 266 Precambrian: Insight from numerical experiments, Lithos, 116, 209-229 (2010).

267 18. Zhong, S., Davies, G. F. Effects of plate and slab viscosities on the geoid. Earth 268 Planet. Sci. Let. 170, 487-496 (1999).

269 19. Billen, M.I., Gurnis, M. Constraints on subducting plate strength within the $270 \quad$ Kermadec trench. J. Geophys. Res. 110, B05407 (2005).

271 20. Petersen, R.I., Stegman, D.R., Tackley, P.J. (2016) The subduction dichotomy of 272 strong plates and weak slabs. Solid Earth, doi:10.5194/se-2016-56. 
273 21. van Summeren, J., Conrad, C. P., Lithgow-Bertelloni, C. The importance of slab 274 pull and a global asthenosphere to plate motions. Geochem. Geophys. Geosys. 275 13, Q0AK03 (2012).

276 22. Garel, F., Goes, S., Davies, D. R., Davies, J. H., Kramer, S. C., Wilson, C. R. 277 Interaction of subducted slabs with the mantle transition-zone: A regime 278 diagram from 2-D thermo-mechanical models with a mobile trench and an 279 overriding plate. Geochem. Geophys. Geosys. 15, 1739-1765, (2014).

280 23. Gerya, T.V., Connolly, J.A.D., Yuen, D.A. (2008) Why is terrestrial subduction one281 sided? Geology, 36(1), 43-46.

282 24. Č́ížková, H., van Hunen, J., van den Berg, A.P., Vlaar, N.J. The influence of 283 rheological weakening and yield stress on the interaction of slabs with the 670km discontinuity, Earth Planet. Sci. Lett., 199, 447-457 (2002).

25. Ribe, N. M. Bending mechanics and mode selection in free subduction: a thinsheet analysis. Geophys. J. Int. 180,559-576 (2010).

26. Ghosh, A.; Becker, T. W.; Zhong, S. J. Effects of lateral viscosity variations on the geoid. Geophys. Res. Let. 37 , L01301 (2010).

27. Karato, S., Wu, P. (1993) Rheology of the upper mantle: a synthesis. Science 260, 771-778.

28. Ranalli, G. Rheology of the Earth (Chapman and Hall, 1995).

29. Mishin, Y.A., Gerya, T.V., Burg, J.-P., Connolly, J.A.D. Dynamics of double subduction: Numerical modeling. Physics of the Earth and Planetary Interiors, 171, 280-295 (2008).

30. Funiciello, F., Faccenna, C., Heuret, A., Lallemand, S., Di Giuseppe, E., Becker, T. W. Trench migration, net rotation and slab-mantle coupling. Earth Planet. Sci. Lett. 271, 233-240

31. Liu, L. and Stegman, D. R. (2011) Segmentation of the Farallon slab, Earth and Planetary Science Letters, 311, 1-10.

32. Gerya, T.V., Yuen, D.A. Robust characteristics method for modelling multiphase 302 visco-elasto-plastic thermo-mechanical problems. Phys. Earth Planet. Interiors 163, 83-105 (2007). 
33. Bercovici, D., Ricard, Y. Mechanisms for the generation of plate tectonics by twophase grain-damage and pinning. Phys. Earth. Planet. Inter. 202-203, 27-55 (2012).

34. Bercovici, D., Ricard, Y. Plate tectonics, damage and inheritance. Nature 508, 307 513-516 (2014).

35. Bercovici, D., Schubert, G., Ricard, Y. Abrupt tectonics and rapid slab detachment with grain damage. Proceed. National Acad. Sci. 112, 1287-1291 (2015).

36. Mulyukova, E., Bercovici, D. Formation of lithospheric shear zones: Effect of temperature on two-phase grain damage. Phys. Earth Planet. Inter. 270, 195212 (2017).

37. Mulyukova, E., Bercovici, D. Collapse of passive margins by lithospheric damage and plunging grain size, Earth. Planet. Sci. Lett. 484, 341-352 (2018).

38. Mulyukova, E., Bercovici, D. The generation of of plate tectonics from grains to global scales: A brief review, for special "50th Annivesary of Plate Tectonics" volume of Tectonics 38, 4058-4076 (2019).

39. Gurnis, M., Hall, C., Lavier, L., Evolving force balance during incipient subduction. Geochem. Geophys. Geosyst. 5, Q07001 (2004).

40. Lavier, L.L., Buck, W.R., Poliakov, A.N.B. Factors controlling normal fault offset in an ideal brittle layer. J. Geophys. Res. 105, 23431-23442 (2000).

41. Choi, E., Lavier, L., Gurnis, M., Thermomechanics of mid-ocean ridge segmentation. Phys. Earth Planet. Inter. 171, 374-386 (2008).

42. Whitney, D.L., Teyssier, C., Rey, P., Buck, W.R. Continental and oceanic core complexes. Geol. Soc. Am. Bulletin 125, 273-298 (2013).

43. Hirauchi, K., Fukushima, K., Kido, M., Muto, J., Okamoto, A. Reaction-induced rheological weakening enables oceanic plate subduction. Nat. Commun. 7, 12550 (2016).

44. Duretz, T. et al. The importance of structural softening for the evolution and architecture of passive margins. Sci. Rep. 6, 1-7 (2016)

45. John,T. et al. Generation of intermediate-depth earthquakes by self-localizing thermal runaway. Nat. Geosci. 2, 137-140 (2009). 
46. Pozzi, G. et al. Coseismic ultramylonites: An investigation of nanoscale viscous flow and fault weakening during seismic slip. Earth Planet. Sci. Let. 516, 164175 (2019).

47. Verberne, B.A. et al. Microscale cavitation as a mechanism for nucleating earthquakes at the base of the seismogenic zone. Nat. Commun. 8, 1645 (2017).

48. Dymkova, D., Gerya, T. Porous fluid flow enables oceanic subduction initiation on Earth. Geophysical Research Letters, 40, 5671-5676 (2013).

49. Brace, W. F., Kohlstedt, D. T. Limits on lithospheric stress imposed by laboratory experiments. J. Geophys. Res. 85, 6248-6252 (1980).

50. Byerlee, J. D. Friction of rocks. Pure Applied Geophys. 116, 615-626 (1978).

\section{Methods}

346 Modeling approach. The thermo-mechanical 2D numerical code I2VIS is used for the 347 modeling of subduction initiation. It is based on a combination of a finite difference 348 method, applied on a staggered Eulerian grid, and a marker-in-cell technique ${ }^{51,52}$. The 349 momentum, mass and energy conservation equations are solved in an Eulerian frame, and

350 physical properties are transported by Lagrangian. Non-Newtonian, visco-plastic 351 rheologies and variable thermal conductivity are used in the model (Extended Data 352 Table 1) $)^{27,28,53-57}$, which accounts for major phase transitions in the oceanic crust and 353 mantle as well as adiabatic, radiogenic and frictional internal heating sources. Full details 354 of this method, allowing for its reproduction, are provided elsewhere ${ }^{51,52}$.

356 Numerical model design. The initial model setup (Extended Data Fig. 1) corresponds to the 357 one used for spontaneous subduction initiation at an oceanic transform fault ${ }^{23,39}$. The 358 computational domain is equivalent to $3000 \times 3000 \mathrm{~km}$ (Extended Data Fig. 1) and is 359 resolved with an irregular rectangular grid of $1261 \times 511$ nodes and contains 19 million 360 randomly distributed markers. All sides of the model have free slip mechanical boundary 361 conditions. The free surface boundary condition atop the crust is implemented by using a $36212 \mathrm{~km}$ thick "sticky" air/water layer ${ }^{58}$ with low density $\left(1 \mathrm{~kg} / \mathrm{m}^{3}\right.$ above $9 \mathrm{~km}, 1000 \mathrm{~kg} / \mathrm{m}^{3}$ 363 below $9 \mathrm{~km})$ and viscosity $\left(10^{17} \mathrm{~Pa} \mathrm{~s}\right)$. The initial thermal structure and thickness of the 
364 plate (Extended Data Fig. 1) is defined by prescribing a laterally uniform cooling age and 365 respective geotherm ${ }^{54}$ with $273 \mathrm{~K}$ at the surface and the mantle potential temperature of 366 1523-1823 K varied in different experiments (Extended Data Table 2). We explored two 367 types of model setups with different initial conditions. In models with free subducting plate, 368 within $500 \mathrm{~km}$ at the right model boundary the subducting plate age gradually decreases 369 toward $1000 \mathrm{yr}$ that corresponds to weak mid-ocean ridge located at the boundary 370 (Extended Data Figure 1a). In models without with subducting plate attached to the right 371 model boundary, subducting plate age remains unchanged toward the boundary (Extended 372 Data Figure 1a). An adiabatic gradient of $0.5 \mathrm{~K} / \mathrm{km}$ is initially prescribed in the 373 asthenospheric mantle (Extended Data Fig. 1). Within $500 \mathrm{~km}$ at the lower boundary 374 temperature increases linearly by $744 \mathrm{~K}$ to mimic the hot boundary layer at the core-mantle 375 boundary. Temperature-dependent thermal conductivity is used for the mantle and the crust 376 (Extended Data Table S1). The thermal boundary conditions are $273 \mathrm{~K}$ at the top, 3567$3773717 \mathrm{~K}$ (depending on the mantle potential temperature) at the bottom and zero heat flux 378 on two other sides of the model. In order to insure efficient heat transfer from the surface 379 of the crust, the temperature of the "sticky" air/water is kept constant at $273 \mathrm{~K}$. 380 Gravitational acceleration of $9.81 \mathrm{~m} / \mathrm{s}^{2}$ has been used in the model.

381 The surface of the lithosphere evolves by erosion and sedimentation according 382 to the following Eulerian transport equation ${ }^{59}$,

$383 \quad \frac{\partial z_{e s}}{\partial t}=v_{z}-v_{x} \frac{\partial z_{e s}}{\partial x}-v_{s}+v_{e}$,

384 where $x$ and $z$ are horizontal and vertical coordinates, respectively, $z$ es is the vertical 385 position of the surface as a function of the horizontal distance $x, v_{z}$ and $v_{x}$ are the 386 vertical and horizontal components of the material velocity vector at the surface, 387 and $v_{s}$ and $v_{e}$ are the sedimentation and erosion rates, respectively. The 388 sedimentation and erosion rates correspond to the following relations ${ }^{60}$, $389 \tau_{\mathrm{s}}=0 \mathrm{~mm} / \mathrm{yr}, v_{\mathrm{e}}=0.3 \mathrm{~mm} / \mathrm{yr}$, when $z<9 \mathrm{~km}$ (the sea-level prescribed in the model), 390 and $v_{\mathrm{s}}=0.03 \mathrm{~mm} / \mathrm{yr}, v_{\mathrm{e}}=0$, when $z>z_{\mathrm{sea}}$. The maximal surface slope for the 391 accumulated sedimentary prism is limited by $17^{\circ}$. Surface processes however play 392 relatively minor role for subduction dynamics and slab morphology in our 
393 numerical experiments as follows from test runs without surface processes

394 (Extended Data Table 2).

395

Density model. We use the extended Boussinesq approximation with incompressible continuity equation and variable density in the momentum and energy conservation equations. The density of rocks varies with pressure $(P)$ and temperature $(T)$ according to the equation,

$$
\rho_{\mathrm{P}, \mathrm{T}}=\rho_{0}\left[1-\alpha\left(T-T_{0}\right)\right]\left[1+\beta\left(P-P_{0}\right)\right],
$$

where $\rho_{0}$ is the standard density at $P_{0}=1 \mathrm{MPa}$ and $T_{0}=298 \mathrm{~K}$, and $\alpha \square=\square 2 \times 10^{-5} 1 / \mathrm{K}$

402 and $\beta \square=4.5 \times 10^{-12} 1 / \mathrm{Pa}$ are the coefficients of thermal expansion and compressibility, 403 respectively (Extended Data Table 1).

404 Our models take into account the phase transformations of olivine into 405 wadsleite-and ringwoodite ${ }^{61}$ and into bridgmanite in the mantle ${ }^{62}$. Eclogitization of 406 subducted basaltic and gabbroic crust is taken into account by linearly increasing 407 the density of the crust with pressure from $0 \%$ to $16 \%$ in the $P$ - $T$ region between 408 the experimentally determined garnet-in and plagioclase-out phase transitions in 409 basalt ${ }^{63}$. The physical parameters for each experiment are presented in Extended 410 Data Table 2.

412 Visco-plastic rheological model. The viscous and brittle (plastic) properties (see Extended 413 Data Table 1) are implemented via evaluation of the effective viscosity of the material. For 414 the ductile rheology, the contributions from different flow laws such as dislocation and 415 diffusion creep are taken into account by composite rheology for $\eta$ ductile

$416 \frac{1}{\eta_{\text {ductile }}}=\frac{1}{\eta_{\text {diff }}}+\frac{1}{\eta_{\text {disl }}},(1)$

$417 \eta_{d i f f}$ and $\eta_{\text {disl }}$ are effective viscosities for diffusion and dislocation creep, respectively.

418 For the crust, constant grain size is assumed and $\eta_{\text {diff }}$ and $\eta_{\text {disl }}$ are computed as

$419 \eta_{\text {diff }}=\frac{A}{2 \sigma_{\mathrm{cr}}^{n-1}} \exp \left(\frac{E+P V}{R T}\right)$,

$420 \quad \eta_{\text {disl }}=\frac{1}{2} A^{\frac{1}{n}} \exp \left(\frac{E+P V}{n R T}\right) \dot{\varepsilon}_{\text {II }}^{\frac{1}{n}-1}$, 
421 where $R$ is gas constant, $P$ is pressure, $T$ is temperature (in $\mathrm{K}$ ), $\dot{\varepsilon}_{\mathrm{II}}=\sqrt{1 / 2\left(\dot{\varepsilon}_{i j}\right)^{2}}$ is the 422 square root of the second invariant of the strain rate tensor, $\sigma_{\mathrm{cr}}$ is the assumed diffusion423 dislocation transition stress, and $A, E, V$ and $n$ are experimentally determined pre424 exponential factor, activation energy, activation volume and stress exponent of the viscous 425 creep, respectively (Extended Data Table 1), which stand for the material constant, the 426 activation energy, the activation volume and the stress exponent, respectively.

428 For the mantle, the ductile creep model also takes into account grain size reduction and 429 growth processes assisted by Zener pinning, and $\eta_{\text {diff }}$ and $\eta_{\text {disl }}$ are computed as ${ }^{33,36,64}$. The 430 rheology follows a composite law as in (1), wherein

$431 \quad \eta_{\text {diff }}=\frac{1}{2} A_{\text {diff }} h^{m} \exp \left(\frac{E_{\text {diff }}+P V_{\text {diff }}}{R T}\right)$,

$432 \quad \eta_{\text {disl }}=\frac{1}{2} A_{\text {disl }}^{\frac{1}{n}} \exp \left(\frac{E_{\text {disl }}+P V_{\text {disl }}}{n R T}\right) \dot{\varepsilon}_{\mathrm{II}}^{\frac{1}{n}-1}$,

433 Where $h$ is a mean grain size, $m$ is grain size exponent. The interplay between diffusion 434 and dislocation creep is controlled by a grain-size evolution equation dependent on the 435 mechanical work and temperature. The grain size evolution model relies on several 436 assumptions:

437 (1) Mantle peridotite is assumed to be composed of two well-mixed phases: olivine and 438 pyroxene with a fixed volume fraction of $60 \%$ and $40 \%$, respectively. These phases 439 are considered to have the same density and rheology.

440 (2) In both phases the relative motion is considered to be negligible and therefore their $441 \quad$ velocity $v$ is the same.

442

443

(3) It is assumed that the grain size distribution is close to a self-similar log-normal distribution. Therefore, it always retains the same shape and its mean variance and amplitude are fully characterized by a unique grain size.

445 We make the further assumption that the system is in a state known as pinned state limit ${ }^{33,35}$ 446 wherein the grain size evolution is controlled by the pinning of phases by each other (i.e. 447 Zener pinning is dominant $)^{33}$. In these conditions, the grain size is controlled by the 448 roughness $r$ of the interface between the two phases. A relation between the mean grain 449 size $h$ (sufficient to fully describe the system) and the roughness $r$ is given by $h=\frac{r}{\sqrt{h_{g}}}$, 
450 where $h_{g} \approx \frac{\pi}{2}$ for the phase volume fraction in our model ${ }^{35}$. The roughness evolution is

451 described by the following equations ${ }^{33,36,64,65}$

$452 \quad \frac{d r}{d t}=\frac{\eta G_{I}}{q r^{(q-1)}}-\frac{f_{I} r^{2}}{\gamma_{I} \eta} \Psi(6)$

$453 \quad G_{I}=\frac{G_{g}}{G_{f a c}} \frac{q}{p} r^{(q-p)},(7)$

$454 \quad G_{g}=A_{g} \exp \left(\frac{E_{g}+P V_{g}}{R T}\right)$,

$455 f_{I}=f_{0} \exp \left(-2\left(\frac{T}{1000}\right)^{2.9}\right)$

456 where $G_{I}$ is interface coarsening, $G_{g}$ is grain growth rate, $G_{f a c}=100$ is grain growth rate

457 factor, $q=4$ is roughness coarsening exponent, $p=2$ is grain size coarsening exponent, $f_{I}$

458 is damage at the given temperature $T, A g=2 \times 10^{(4-6 p)}$ is pre-exponential factor, $E_{g}=3 \times 10^{5}$

459 is a grain-growth activation energy, $V_{g}=V_{\text {diff }}$ is a grain-growth activation volume, $f_{I}$ is the

460 fraction of mechanical work $\Psi$ converted to interface damage resulting in grainsize

461 reduction; $f_{0}=0.001$ is interface damage at $1000 \mathrm{~K}, \eta=3 \varphi_{\mathrm{ol}} \varphi_{\mathrm{px}}$ is interface area density

462 depending on the volume fractions of olivine $\left(\varphi_{\mathrm{ol}}=0.6\right)$ and pyroxene $\left(\varphi_{\mathrm{px}}=0.4\right)$ in the 463 mantle.

464 The ductile rheology is combined with a brittle (plastic) rheology to yield an effective

465 viscous-plastic rheology using the following upper limit for the ductile viscosity

$466 \quad \eta_{\text {ductile }} \leq \frac{C+\mu P}{2 \dot{\varepsilon}_{\mathrm{II}}},(4)$

$467 \mu=\mu_{0}-\gamma \mu_{\gamma}$ for $\gamma \leq \gamma_{0}$ and $\mu=\mu_{1}$ for $\gamma>\gamma_{0}$,

$468 \quad \gamma=\int \sqrt{\frac{1}{2}\left(\dot{\varepsilon}_{i j \text { (plastic) })}\right)^{2}} d t$,

469 where $\mu$ is the internal friction coefficient, ( $\mu_{0}$ and $\mu_{1}$ are the initial and final internal 470 friction coefficient, respectively, Extended Data Table 1), $\mu_{\gamma}=\left(\mu_{0}-\mu_{1}\right) / \gamma_{0}$ is the rate of 471 faults weakening with integrated plastic strain $\gamma\left(\gamma_{0}\right.$ is the upper strain limit for the fracture472 related weakening), $C$ is the rock compressive strength at $P=0$ (Extended Data Table 1), $473 t$ is time (s), $\dot{\varepsilon}_{i j \text { (plastic) }}$ is the plastic strain rate tensor. It is also assumed that the mantle 474 inside outer rise normal faults that reached the upper strain limit $\left(\gamma_{0}\right)$ is serpentinized and 475 has the respective rheology (Extended Data Table 1). 


\section{Data availability}

477 All input and output files, used in the numerical modelling and visualisation are available 478 on request.

479 Code availability

480 The numerical modelling code I2VIS and MatLab codes used for visualisation will be 481 made accessible upon the paper acceptance.

482

483 Acknowledgements This work was supported by SNF projects 200021_182069 and 484 200021_192296 (to T.V.G.) and NSF EAR-1853856 (to T.W.B.). The simulations were 485 performed on the ETH-Zurich Euler and Leonhard clusters.

\section{References of Methods}

51. Gerya, T.V., Yuen, D.A., Characteristics-based marker-in-cell method with conservative finite-differences schemes for modeling geological flows with strongly variable transport properties. Phys. Earth Planet. Interiors, 140, 293-318 (2003).

52. Gerya T.V. Introduction to Numerical Geodynamic Modelling. Second edition. (Cambridge Univ. Press, 2019).

53. Hofmeister, A. M. Mantle values of thermal conductivity and the geotherm from Phonon lifetimes. Science, 283, 1699-1706 (1999).

54. Turcotte, D. L. \& Schubert, G. Geodynamics (Cambridge Univ. Press, 2002).

55. Clauser, C., Huenges, E. Thermal conductivity of rocks and minerals. In: Ahrens, T.J. (editor), Rock Physics and Phase Relations. AGU Reference Shelf 3. American Geophysical Union, Washington DC, pp. 105-126 (1995).

502

504 57. Hilairet, N., B. et al. High-pressure creep of serpentine, interseismic deformation, and 505 initiation of subduction. Science, 318, 1910-1913 (2007). 
506 58. Schmeling, H. et al. A benchmark comparison of spontaneous subduction models: Towards a free surface. Phys. Earth Planet. Inter. 171, 198-223 (2008).

508 59. Gerya, T.V., Yuen, D.A. Rayleigh-Taylor instabilities from hydration and melting 509 propel "cold plumes" at subduction zones. Earth and Planet Sci. Lett., 212, 47-62 (2003).

511 60. Baitsch-Ghirardello, B., Gerya, T.V., Burg, J.-P. Geodynamic regimes of intra-

512 oceanic subduction: Implications forearc extension vs. shortening processes.

513 Gondwana Res. 25, 546-560 (2014).

514 61. Katsura, T., \& Ito, E. The system Mg2SiO4-Fe2SiO4 at high pressures and

515 temperatures: Precise determination of stabilities of olivine, modified spinel, and

516 spinel. J. Geophys. Res., 94, 663-670 (1989).

517 62. Ito, E. et al. Negative pressure-temperature slopes for reactions forming MgSiOa

518 perovskite from calorimetry. Science 2J9, 1275-1278 (1990).

519 63. Ito, K. \& Kennedy, G.C. in The Structure and Physical Properties of the Earth's Crust (ed Heacock, J.G.) 303-314 (Geophysical Monograph Series 14, AGU, 1971).

521 64. Bercovici, D., Ricard, Y. Generation of plate tectonics with two-phase grain-damage 522 and pinning: Source-sink model and toroidal flow. Earth Planet. Sci. Lett. 365, 275-

$523288(2013)$.

524 65. Rozel, A., Ricard, Y., Bercovici, D. A thermodynamically self-consistent damage 525 equation for grain size evolution during dynamic recrystallization. Geophys. J. Int. $526 \quad 184,719-728(2011)$.

528 Author Information. The authors declare no competing financial interests.

529 Correspondence and requests for materials should be addressed to T.G. 530 (taras.gerya@erdwethz.ch). 


\section{Figure legends}

Figure 1. Dynamics of subduction and slab segmentation for $40 \mathrm{Ma}$ old oceanic plate with $8 \mathrm{~km}$ thick crust formed under present day mantle temperature conditions (model xbeq, Extended Data Table S2). Left - evolution of viscosity structure. Right evolution of grain size in the mantle. Left and right columns show evolution of viscosity structure and mantle grain size, respectively. Solid black lines indicate position of $1225^{\circ} \mathrm{C}$ isotherm.

Figure 2. Development of large-offset normal faults in the numerical model a, b (model xbeq, Extended Data Table S2, Fig. 1) and at the Japan $\operatorname{trench}^{9}$ c, d. Solid black lines in $\mathrm{a}, \mathrm{b}$ indicate position of $1225^{\circ} \mathrm{C}$ isotherm.

Figure 3. Influence of faults weakening and grain size evolution on subduction dynamics: a - model with both faults weakening and grain size evolution (model xbeqc, Extended Data Table S2), b - model with faults weakening but without grain size evolution (model xbeqca, Extended Data Table S2), c - model with grain size evolution but without faults weakening (model xbeqcb, Extended Data Table S2), d - with neither fault weakening nor grain size evolution (model xbeqcc, Extended Data Table S2). Mantle temperature is taken $100 \mathrm{~K}$ higher than present day values. Other parameters are the same as in the reference model (Fig. 1). Solid black lines indicate position of $1225^{\circ} \mathrm{C}$ isotherm.

Figure 4. Influence of model parameters on subduction dynamics in models with standard grain size evolution: a - failed subduction initiation in the model with $40 \mathrm{Ma}$ subducting plate but without faults weakening (model xbeqab, Extended Data Table $\mathrm{S} 2), \mathrm{b}$ - no slab segmentation in the model with 40 Ma subducting plate but with 2.5 times slower rate of faults weakening with strain (model xbes, Extended Data Table 
S2), c - reference slab segmentation model with 40 Ma subducting plate and standard faults weakening (model xbeq, Fig. 1, Extended Data Table S2), d - longer slab segments in the model with $100 \mathrm{Ma}$ subducting plate and standard fault weakening (model xber, Extended Data Table S2). Mantle temperature is taken at present day values. Other parameters are the same as in the reference model (Fig. 1). Solid black lines indicate position of $1225^{\circ} \mathrm{C}$ isotherm.

Figure 5. Comparison of subduction dynamics for the models with a (model xbeqd, Extended Data Table S2) and without b (model xbeqda, Extended Data Table S2) grain size evolution. Mantle temperature is taken $150 \mathrm{~K}$ higher than present day values. Other parameters are the same as in the reference model (Fig. 1). Solid black lines indicate position of $1225^{\circ} \mathrm{C}$ isotherm.

\section{Extended Data figure legends}

Extended Data Figure 1. Initial conditions for two types of subduction models explored in this study. a - model setup with free subducting plate detached from the right model boundary; subducting plate age changes to $1000 \mathrm{yr}$ linearly with the distance within $500 \mathrm{~km}$ at the right model boundary. $\mathrm{b}$ - model setup with subducting plate attached to the right model boundary; subducting plate age does not change toward the boundary. White lines with numbers are isotherms in ${ }^{\circ} \mathrm{C}$. 


\section{Figures}

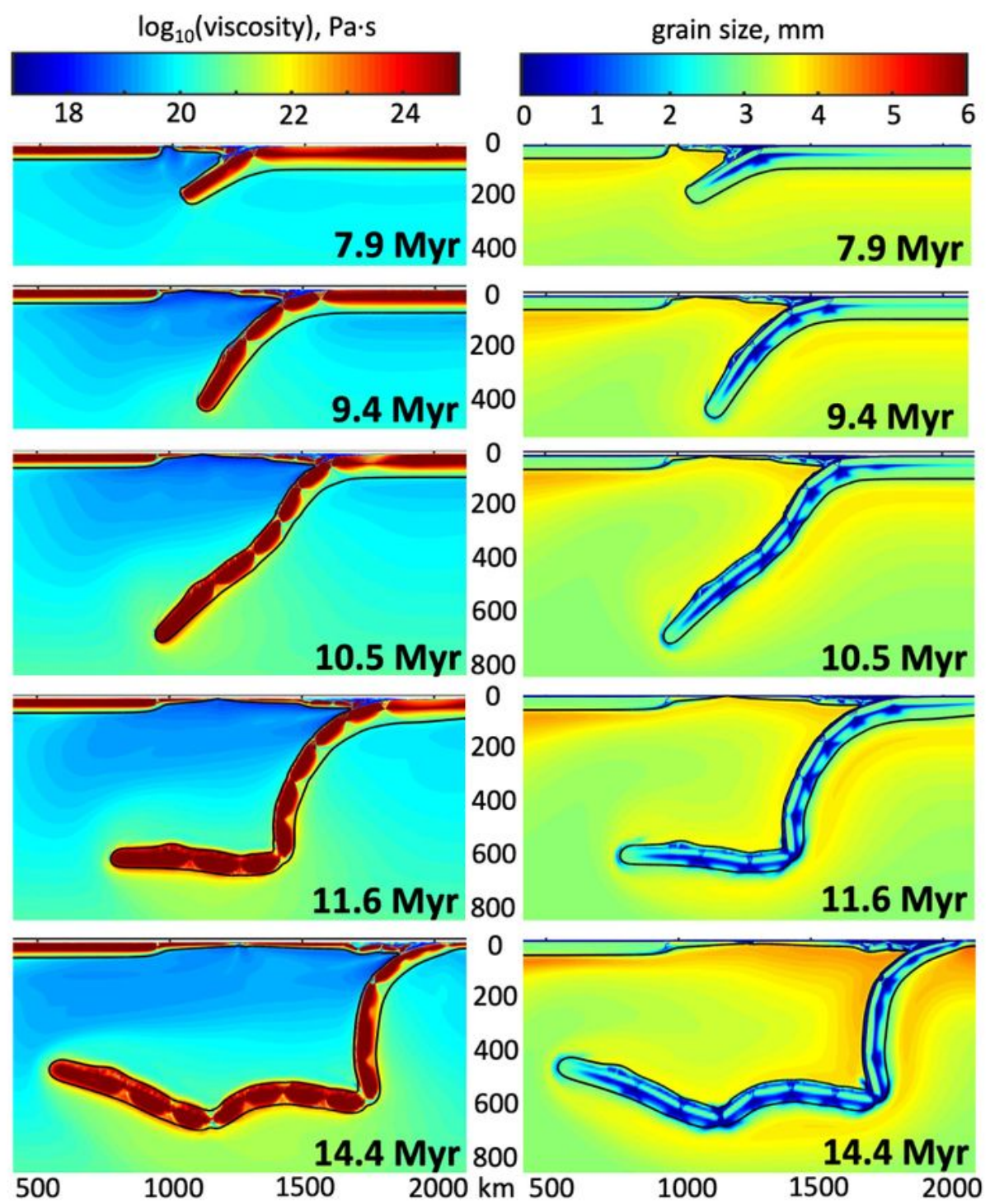

\section{Figure 1}

Dynamics of subduction and slab segmentation for $40 \mathrm{Ma}$ old oceanic plate with $8 \mathrm{~km}$ thick crust formed under present day mantle temperature conditions (model xbeq, Extended Data Table S2). Left - evolution of viscosity structure. Right -evolution of grain size in the mantle. Left and right columns show evolution 
of viscosity structure and mantle grain size, respectively. Solid black lines indicate position of $12250 \mathrm{C}$ isotherm.
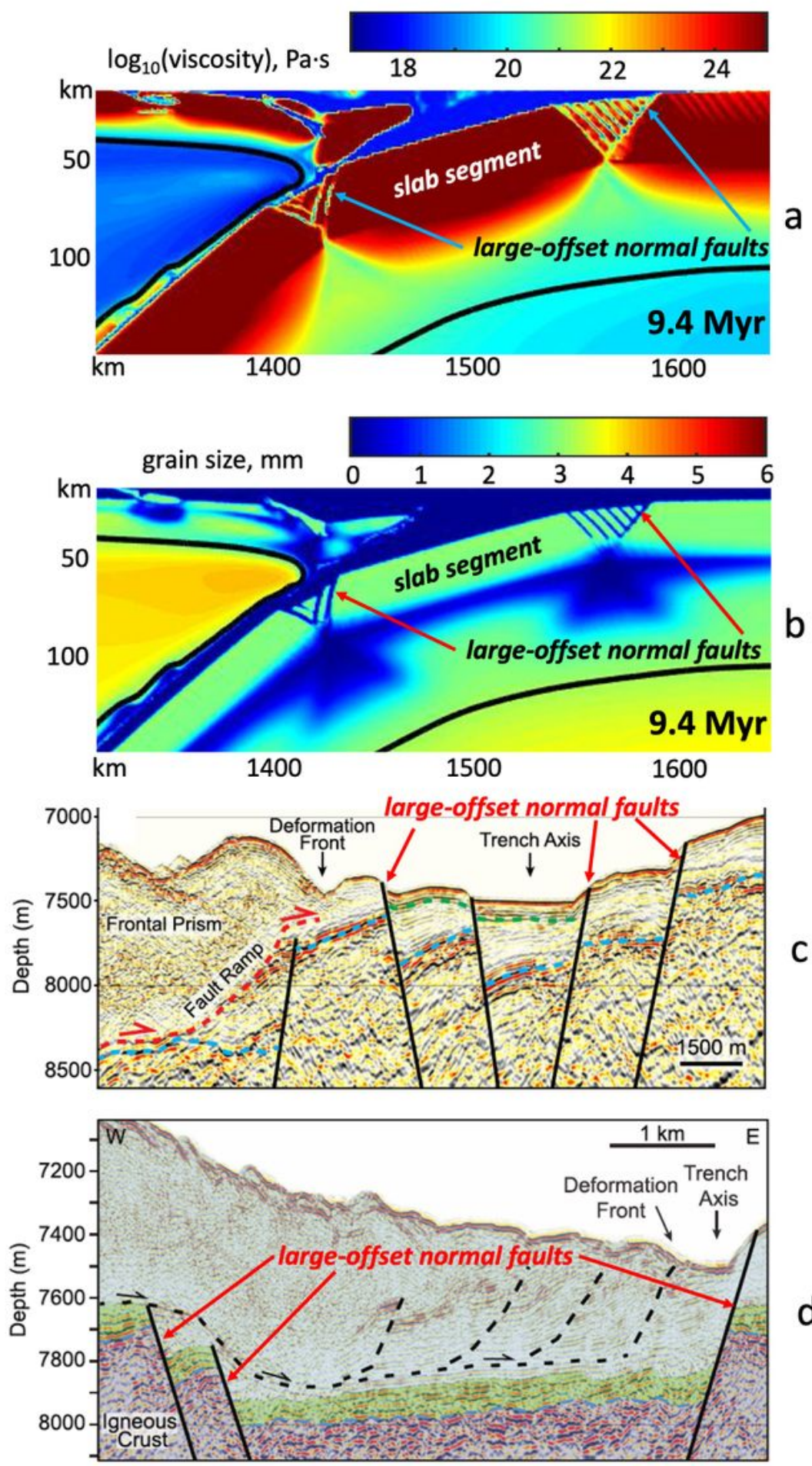

\section{Figure 2}

Development of large-offset normal faults in the numerical model a, b (model xbeq, Extended Data Table S2, Fig. 1) and at the Japan trench9 c, d. Solid black lines in a, b indicate position of $12250 \mathrm{C}$ isotherm. 


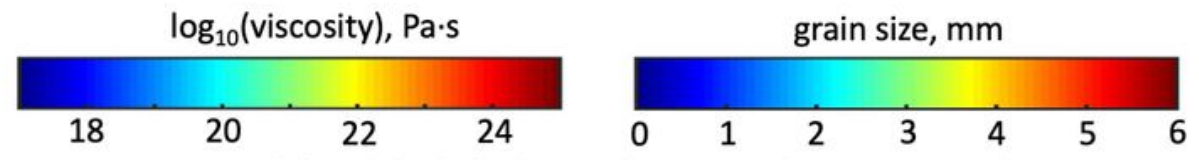

a model with both faults weakening and grain size evolution
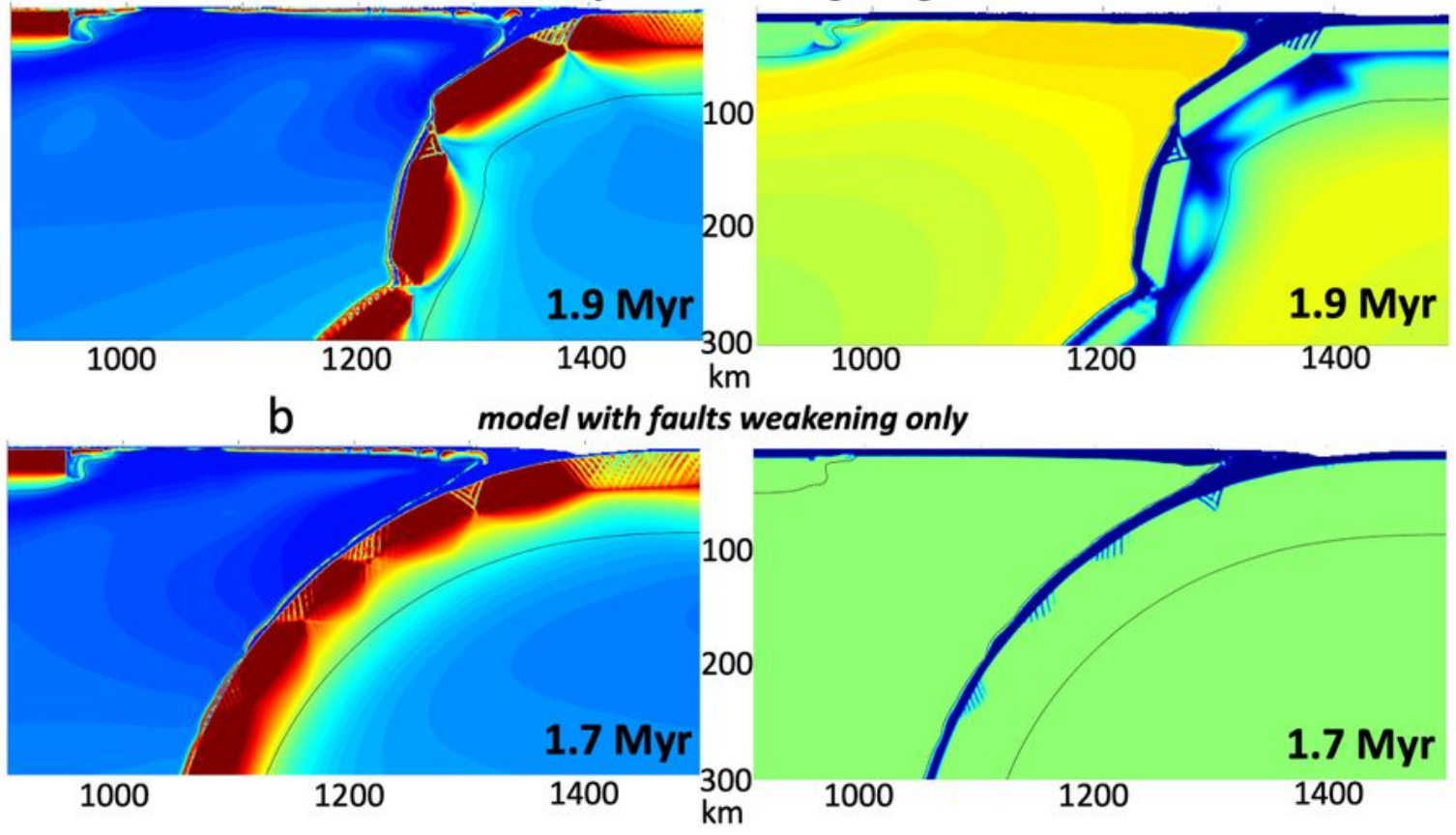

C model with grain size evolution only
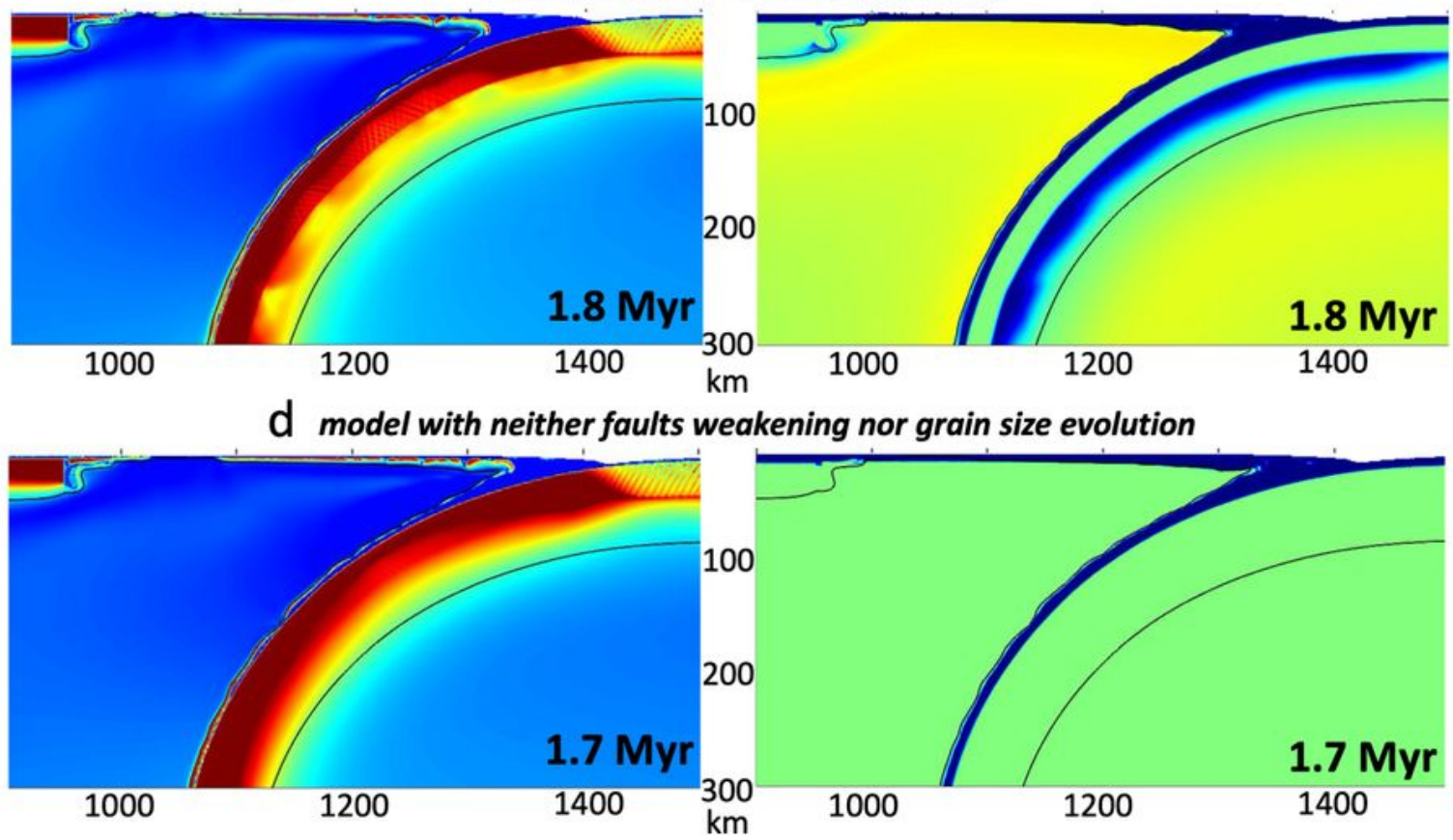

Figure 3

Influence of faults weakening and grain size evolution on subduction dynamics: a - model with both faults weakening and grain size evolution (model xbeqc, Extended Data Table S2), b - model with faults weakening but without grain size evolution (model xbeqca, Extended Data Table S2), c - model with grain size evolution but without faults weakening (model xbeqcb, Extended Data Table S2), $d$ - with neither fault weakening nor grain size evolution (model xbeqcc, Extended Data Table S2). Mantle temperature is 
taken $100 \mathrm{~K}$ higher than present day values. Other parameters are the same as in the reference model (Fig. 1). Solid black lines indicate position of $12250 \mathrm{C}$ isotherm.
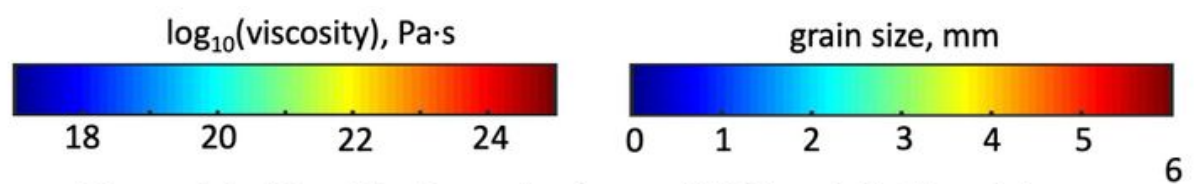

a model without faults weakening and $\mathbf{4 0} \mathrm{Ma}$ subducting plate
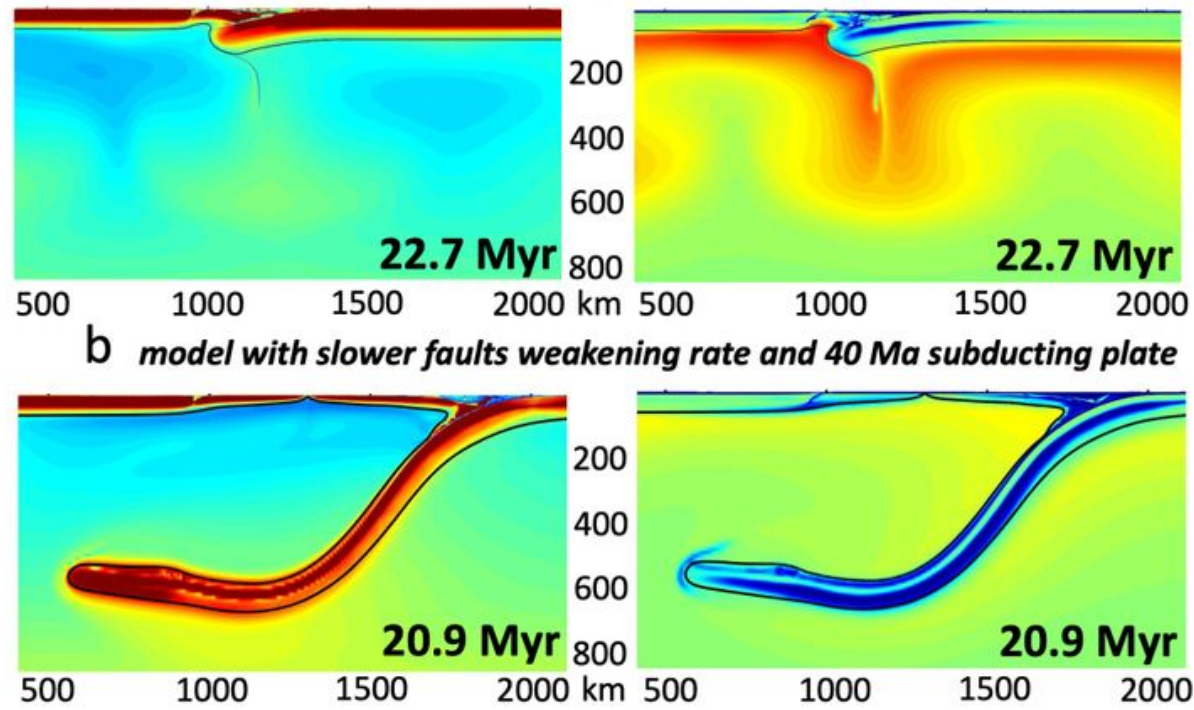

C model with standard faults weakening and $40 \mathrm{Ma}$ subducting plate
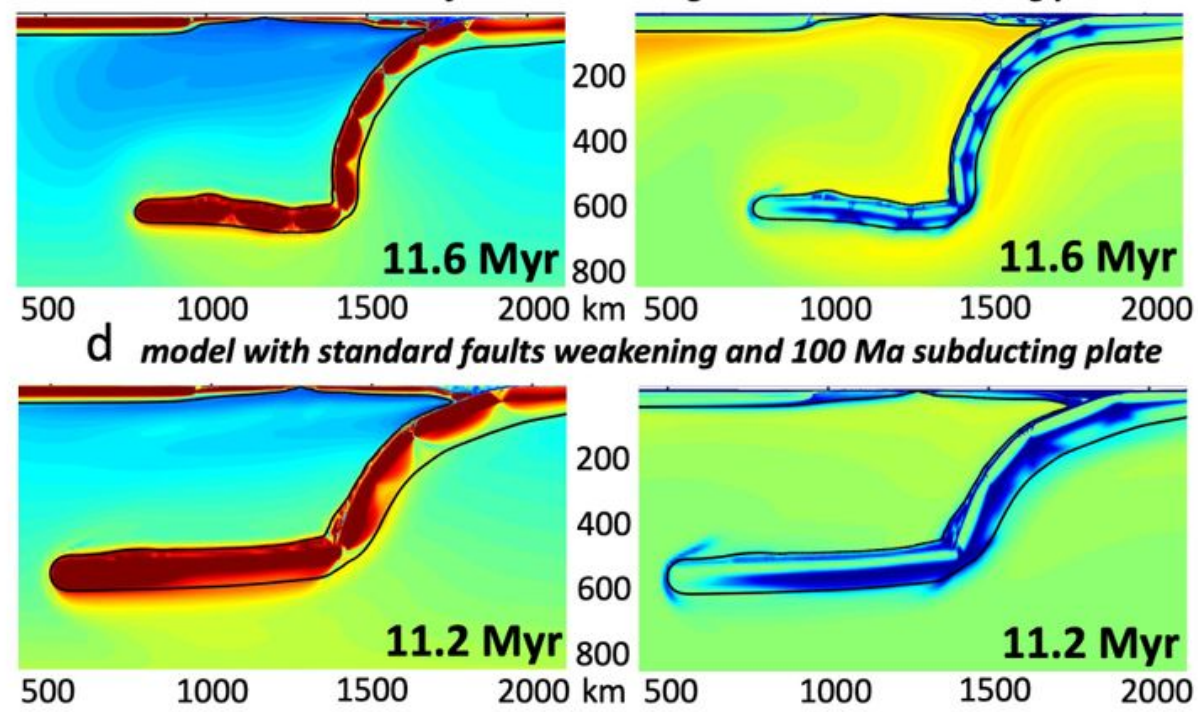

\section{Figure 4}

Influence of model parameters on subduction dynamics in models with standard grain size evolution: a failed subduction initiation in the model with $40 \mathrm{Ma}$ subducting plate but without faults weakening (model xbeqab, Extended Data Table S2), b - no slab segmentation in the model with 40 Ma subducting 
plate but with 2.5 times slower rate of faults weakening with strain (model xbes, Extended Data Table S2), c - reference slab segmentation model with 40 Ma subducting plate and standard faults weakening (model xbeq, Fig. 1, Extended Data Table S2), d - longer slab segments in the model with $100 \mathrm{Ma}$ subducting plate and standard fault weakening (model xber, Extended Data Table S2). Mantle temperature is taken at present day values. Other parameters are the same as in the reference model (Fig.

1). Solid black lines indicate position of $12250 \mathrm{C}$ isotherm.

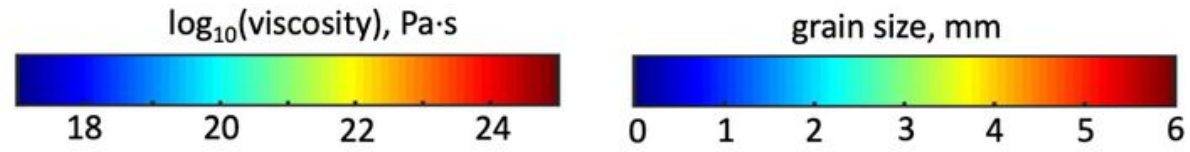

a model with $150 \mathrm{~K}$ hotter mantle and grain size evolution

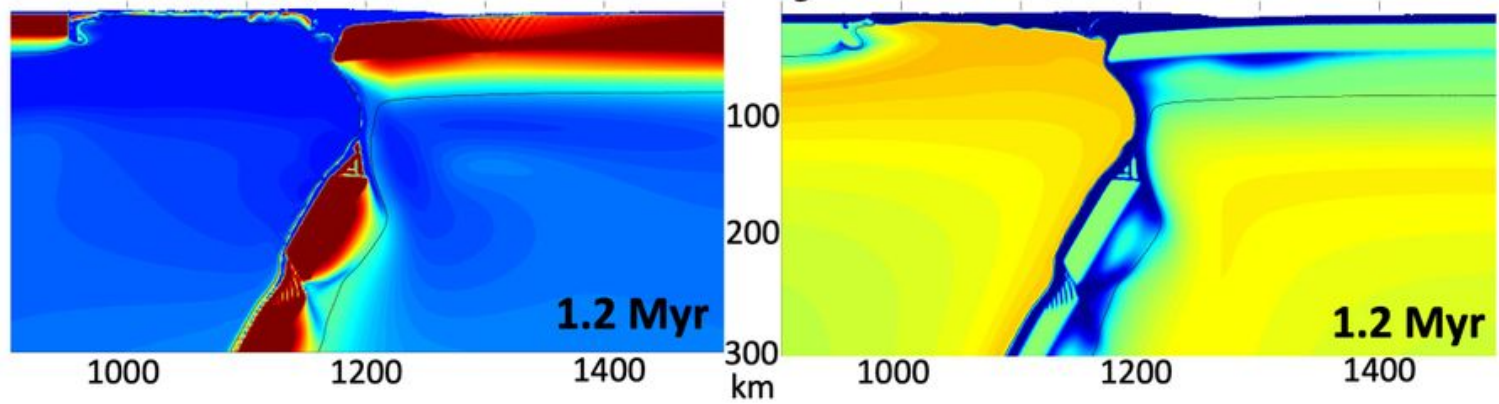

b model with $150 \mathrm{~K}$ hotter mantle but without grain size evolution

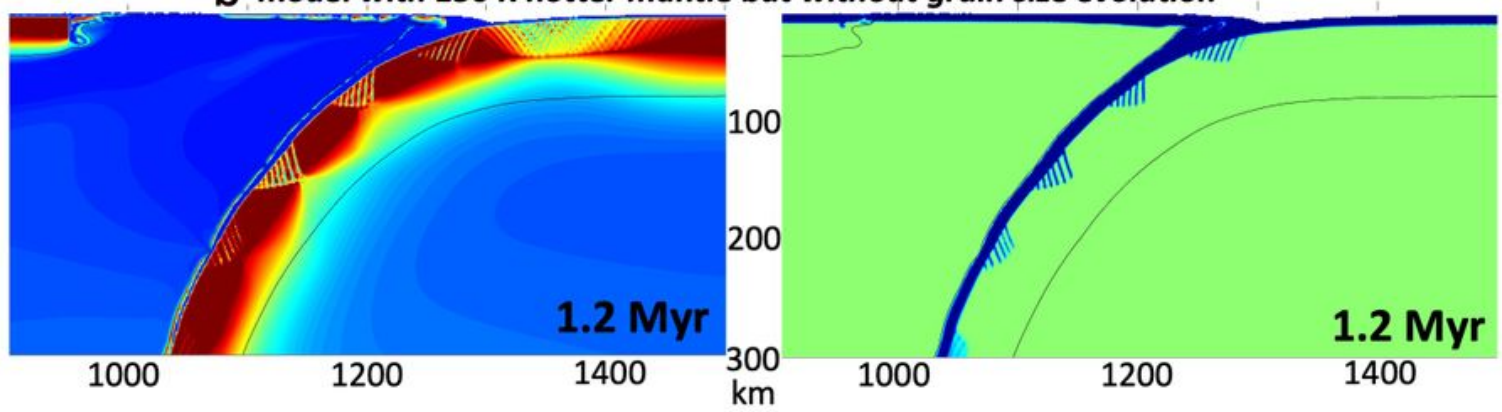


Comparison of subduction dynamics for the models with a (model xbeqd, Extended Data Table S2) and without b (model xbeqda, Extended Data Table S2) grain size evolution. Mantle temperature is taken 150 $\mathrm{K}$ higher than present day values. Other parameters are the same as in the reference model (Fig. 1). Solid black lines indicate position of $12250 \mathrm{C}$ isotherm.

\section{Supplementary Files}

This is a list of supplementary files associated with this preprint. Click to download.

- ExtendedDataTable1.docx

- ExtendedDataTable2.docx

- ExtendedDataFigure1.jpg 